\title{
Botany through the Looking Glass: Cognitive Neuroscience and its Role in the Use of Art in Botanical Education
}

\author{
William Swann ${ }^{\mathrm{a}}$ and Matthew Pye ${ }^{\mathrm{a}}$ \\ Corresponding author: William Swann (swan@anatomy.usyd.edu.au) \\ ${ }^{a}$ School of Life and Environmental Sciences, The University of Sydney
}

Keywords: botany, neuroscience, education, memory, art

\begin{abstract}
Student engagement within the discipline of Botany is not always limited to scientific content. The patterns, colours and shapes that are produced when investigating plant anatomy via sectioning are highly aesthetic and can immediately engage students. The boundaries between aesthetics and science are often blurred or, more correctly, imagined. Nurturing and developing the inspiration drawn from the integration of these two worlds provides an alternative way of engaging students in the theoretical content of the discipline. Student exposure and engagement with native Australian Flora and botanical education is too often limited and finding novel ways to engage students with Botany is critically important; even more so in this current era of Plant Blindness and climate change denial (Jacobson et al., 2016; Wandersee \& Schussler, 2000). To combat this, contemporary neuroscience and cognitive psychology research show promise toward the use of visual mediums to enhance memory, leading to an improvement in educational outcomes (Bigelow \& Poremba, 2014; Cohen, Horowitz, \& Wolfe, 2009; Corballis, 1966; Gloede, 2015; Jensen, 1971; Kim \& Olaciregui, 2008). Therefore, encouraging students to engage with botanical content, via microscopic imagery, scientific/artistic depictions, and more specifically, the production of drawings and artworks (Fernandes et al., 2018; Rosier, Locker, \& Naufel, 2013) should be further incorporated into curricula to increase engagement and establish a deeper connection to Botanical subdisciplines such as plant taxonomy, morphology and systematics. In this paper, with reference to established research and an example of a science-art project, we discuss the ways in which the fusion of the aesthetic and scientific worlds creates a feedback loop from which the creative process inspired from scientific material develops a deeper enquiry-based understanding of the material itself
\end{abstract}

\section{Teaching Botany in the modern world}

Botany, as the exploration of the wonder and vast complexity found within the plant kingdom, reached its height with the boom of the Scientific Revolution and the Age of Enlightenment (Reed, 1942). With the natural unfolding of forms through botanical illustrations, and with evolving intellectual ones, botany was celebrated as new exotic flora was being discovered around the world under the watchful eye of science and reason. The documentation of this inspired and delighted. Along with the expansion of the printing press making these images increasingly accessible to the growing middle classes, this greatly enhanced the allure of the natural sciences as a whole (Breidbach, 2005).

More recently however, there seems to be less of a societal interest in botany, with a noticeable shift to a more 'animal-centric', or 'zoo-chauvinistic', focus in the life sciences (Darley, 1990; Uno, 1994; Wandersee \& Schussler, 2000). As the source of all energy for the animal kingdom, 
the question needs to be asked: why is plant life so readily dismissed? Perhaps it is because the majority of modern urban society has a remarkably reduced role in the handling, cultivation and manufacturing of the raw materials behind the production of foods and goods. While industrialisation is partly to blame for this cultural disconnect from the significance of plant life, it is also inherently easier to relate to the animal kingdom as these species more often mimic qualities of ourselves. This bias is then perpetuated throughout educational environments from primary to tertiary, reinforcing a perspective that plant taxonomy and physiology is far less important than that of animals. The quality of teaching also interplays with this as many educators are not fully trained and/or interested in the plant sciences (Wandersee \& Schussler, 2000). This unfortunate feedback loop reinforces the status quo.

Looking deeper into the functioning of the human brain provides further insight into the relationship we share with plants. Modern investigations suggest that this relationship is a natural product of our neural circuitry: the human visual information processing centre (Norretranders, 1998). It is here that an enormous amount of visual information is entering our system every second, where the brain has adapted to process only small amounts of information at a time. This information is filtered for qualities that have been evolutionarily advantageous, which involves scanning selectively for moving, unusual or threatening stimuli (Norretranders, 1998). Therefore, as plants are static, non-threatening and tend to blend into the background scenery, in the absence of further knowledge, it is part of our 'human default condition' to filter out botanical information to reduce the cognitive load.

For a group of organisms that we are ultimately dependent on for our food, shelter, clothing, etc. (not to mention the oxygen that we breathe), most of modern society knows very little about the major plant groups (e.g. mosses, ferns, cycads, conifers, angiosperms) let alone their basic physiologies and/or anatomies. This general lack of awareness and intrigue in the botanical world has been coined 'plant blindness' (Wandersee \& Schussler, 2000) which describes the inability to recognise the importance of plant life and their visibility in the surrounding environment. This phenomenon has an inhibitory effect on society's ability to take action on issues such as plant conservation, land management and ultimately the ecological impacts of climate change. With one in eight plant species threatened by extinction due to deforestation and/or changes in climate (Allen, 2003), it is evident that more effective education strategies are required to highlight the importance of Botany to higher education students. This cohort of graduate students will then be responsible for the dissemination of this knowledge to the wider public in order to reverse the aforementioned processes. Two critical factors determine whether a student will remember content or not: the level of attention one pays to it, and the importance and value that one allocates to it (Rugg, 1998). Therefore, students who are engaged as deeply as possible in botanical education through effective teaching methodologies are better equipped to reduce the prevalence and effect of plant blindness on society.

\section{Art within the development of tertiary education}

Higher education institutions have enabled an understanding of the importance of connectivity and collaboration between the fields of science, technology, engineering, maths and medicine (STEMM) (Alberts, 2009; National Research Council, 2009; Fairweather, 2010). However, new insights are suggesting a need to expand this inclusive educational culture to involve the arts and the innovative sciences (Segarra et al., 2018). Restructuring the traditional education models and 
including the arts, has been found to aid students' development of important skills that improve learning outcomes such as increasing exploration, observation, self-awareness, and collaboration ( Moga, Burger, Hetland, \& Winner, 2000). Recognising this, new flexible STEAM curricula have currently been developed and implemented across most Australian and international universities allowing these benefits to be readily achievable.

Exercising creativity through the creative arts has also been suggested to have a beneficial impact on educational outcomes, improving academic achievement and perseverance (Darby \& Catterall, 1994). In fact, It is shown to be a determining factor in the success of high impact innovative scientists, with Nobel laureates being almost three times as likely to have a creative avocation than Members of the Royal Society (Root-Bernstein et al., 2008). Scientific research is highly dependent on one's ability to use visual forms of creative thinking (Root-Bernstein, Bernstein, \& Garnier, 1995) and the exercising of this (rather than intellectual reasoning alone) is where Einstein believed many of his insights came from, including that the greatest scientists are artists as well (Einstein, Calaprice, \& Dyson, 2000). This is reflected in the Biology Standards statement provided by the Australian Government and the Office for Learning and Teaching (Ross, Taylor, Johnson, \& Jones, 2013) stating that:

Biology graduates will understand that the creation of biological knowledge is often the consequence of curiosity and innovation. Biology graduates need opportunities to be creative and curious in conducting experiments and research during their undergraduate studies. This means that undergraduate learning experiences should include opportunities for discovery, for exploration and for making novel connections.

Two critical aspects of creativity seem to be of most importance: the ability to solve problems involving seemingly unrelated tasks and the ability to take risks and learn from failure (Sparks, 2011). Therefore, the graduate attributes of creativity and ingenuity, as opposed to grades alone, have been identified as crucial contributors to the success of students in the future by governments, education institutions, and employers. The ability to 'Bend, Break and Blend' are important qualities in STEMM education preparing students for the creative based jobs of the future (Eagleman \& Brandt, 2017). Therefore, it is the responsibility of STEMM learning environments to cultivate divergent thinking alongside convergent thinking in order to spark intellectual curiosity, critical thinking and the development of novel insights (Kraft, 2005).

Herein lies the reasoning behind the integration of art methodologies into the science education. The evidence for this however, is still anecdotal with findings suggesting that the creative thinking skills gained from these practices may transfer to related subjects but not beyond (Moga et al., 2000; Sparks, 2011). Nevertheless, some reports have shown art-science partnerships to be greatly transformative and have yielded unexpected educational rewards (Gurnon, Voss-Andreae, \& Stanley , 2013; Jacobson et al., 2016). Complimenting this, new research in the fields of cognitive psychology and neuroscience is uncovering compelling evidence to support the improvement in learning outcomes associated with the incorporation of visual media, drawing and art making into the curriculum (Fernandes et al., 2018; Rosier et al., 2013; Goldberg, 2005; Runco \& Sakamoto, 1999; Martindale, 1998). 


\section{The modern cognitive neuroscience of visual media on memory and its application in education}

A growing body of cognitive psychology, neuroscience and educational research has allowed us to further understand the functional brain connectivity that allows information to be integrated into long-term memory (Bolwerk et al., 2014; Guy \& Byrne, 2013; Kelley \& Whatson, 2013; MunozLopez et al., 2010; Mohedano-Moriano et al., 2007). These insights can inform the development of novel educational methodologies and technologies to improve teaching quality, leading to increased engagement and motivation, and deeper learning (Guy \& Byrne, 2013; Ramsden, 1992).

Focusing on varying the modes in which information is conveyed, research has shown that student's memory of visual cues is retained far longer than information received through audio perception alone (Bigelow \& Poremba, 2014; Cohen et al., 2009; Corballis, 1966; Gloede, 2015; Jensen, 1971; Kim \& Olaciregui, 2008). This supports a link between visualisation efficiency and cognitive processing (Martindale, 1998; Runco \& Sakamoto, 1999), suggesting that when words and sentences are enhanced with greater meaning, i.e. when associations are made with colours, shapes and images, the memory of the content is improved. This elaborative power has become known as the 'picture-superiority effect', which provides strong evidence for the efficacy of educational information being delivered through visual means, along with the associated verbal labels (noted as 'dual coding') (Clark \& Paivio, 2004; Paivioetal., 1968).

Research has also found that tasks that require processing of visual stimuli relating to the subject matter, lead to students having a higher accuracy and speed of information retrieval than nonvisual tasks, along with the aforementioned improvement in long-term retention (Kim \& Olaciregui, 2008). This improvement suggests that the visual stimuli are processed and integrated differently in the brain, probably in line with the effects of mammalian evolution favoring the efficiency of visual information integration (Kaas, 2013). This has allowed the brain to conserve energy as integrating visual information has the capability to reduce the cognitive load required to process the vast array of information that it is subjected to (Sweller, 1994). Therefore, the brain is likened to a much more effective image processor than a word processor, with more of our visual cortex devoted to vision and the perception of images than to decoding and integrating the abstract nature of words (DeYoe, Lewis, \& Beauchamp, 2000; Scaife \& Rogers, 1996).

Neurophysiological studies show that this 'auditory retention deficit' is due in part by the sparse array of auditory projections in the perirhinal cortex (an important brain region for memory), which is compared to the substantially greater number of neural projections delivered from the visual cortex (Fritz et al., 2005; Mohedano-Moriano et al., 2007; Munoz-Lopez, Mohedano-Moriano, \& Insausti, 2010). This is just one neural explanation for this phenomenon and elaborates on why we should recognise that students will retain information more readily when it is delivered via visual means. Although this reinforces the importance of integrating visual methodologies into processes of learning, even further benefits have been associated with the exploration of visual media through the physical practice of drawing and art making.

\section{Drawing and art as effective teaching modalities}

Along with the effectiveness of visual media to enhance learning, investigations into drawing and art making also demonstrate improvement to memory scores (Fernandes et al., 2018; Rosier et al., 
2013) and enhanced metacognition (Goldberg, 2005) leading to greater retention of the content. This is supported by research promoting drawing and art making as important educational tools that provide a context-rich association with taught content (Meade \& Fernandes, 2016; Van Meter $\&$ Garner, 2005). Furthermore, investigations into processing theory suggest that deep, elaborate and meaningful encoding is most effective at improving later memory retrieval (Hills, Todd, \& Jones, 2015). Therefore, these creative processes show great promise and should be investigated further to help promote learning to a higher level of SOLO taxonomy; meaning a deeper complexity of understanding and an improvement to educational outcomes (Briggs, 1982).

Looking specifically at drawing first, extensive investigations support the beneficial effects of drawing on memory. Illustrating a word's meaning has been shown to lead to a significant enhancement in content retention when compared to writing out or undergoing a verbatim semantic recall of the word alone (Fernandes et al., 2018; Meade \& Fernandes, 2016). Similarly, it has been found that participants drawing whilst receiving an audio conversation recalled $29 \%$ more of the information that was presented than those who did not, with one researcher suggesting that it should be incorporated into work meetings as a strategy to combat day-dreaming distractions (Andrade, 2010). This 'drawing effect' is driven by the integrated contributions of 'motoric, elaborative and pictorial' information processing. That is; the combination of motor processing, semantics (translating several concepts and words into characteristics you can draw) and the obvious visual component (the image that is created). Remarkably, drawing was shown to have a significant benefit after just 4 seconds of drawing during memory encoding, clearly supporting it as a robust memory strategy applicable to education (Fernandes et al., 2018).

Complementary to this, there has also been research performed on the relationship between art and memory (Andrade, 2010; Fernandes et al., 2018; Martindale, 1998; Rosier et al., 2013; Runco \& Sakamoto, 1999). Findings have demonstrated that students who completed an activity that involved viewing and producing an original work of art performed better in a working memory test than students who only viewed a work of art, traced a work of art, or completed a piece of writing (Rosier et al., 2013). This experiment controlled against the potential influences of visual and motor processing, or any changes in mood, showing that there was a significant difference between art making and all other tasks. These results suggest that it is the very act of creating art, not just the engagement of visual and motor processing, which has the beneficial effects on working memory. It is also suggested that this cognitive process may help to consolidate abstract relationships that are embedded amongst meaningful concepts (Scaife \& Rogers, 1996) and thus the information is processed from a new perspective and with a deeper level of understanding (Craik \& Lockhart, 1972). This has been mirrored by others (Martindale, 1998; Runco \& Sakamoto, 1999), showing that art creates a receptive window in which people retain the provided content. However how this equates to the integration of information into long term memory is still to be explored where robust research methodologies on testing, memory and retrieval (Chan et al., 2018; Whiffen \& Karpicke, 2017) should be utilised to further assess the efficacy of drawing and art making on memory.

Research on art making has also provided promising insights into its ability to improve critical thinking skills and a plethora of other skills including exploration, observation, and expression which greatly improve the learning outcomes of other subject areas, notably the sciences (Winner, 2007). Moreover, it has been shown via brain fMRI studies that the production of art improved functional connectivity in brain regions associated with psychological resilience when compared 
to merely viewing art on its own (Bolwerk et al., 2014). When investigating clinical settings, visual art interventions have shown multiple psychological and physiological effects such as reducing distress, increasing self-awareness, reducing heart rate, blood pressure and even cortisol levels (Geue et al., 2010; Kaimal, Ray, \& Muniz, 2016; Leckey, 2011; Stuckey \& Nobel, 2010). Therefore it should be said, that the learning outcomes of art making should not be assessed in isolation but rather as an educational tool to strengthen connections to other forms of learning by improving metacognition and resilience, as well as critical and divergent forms of thinking (Abbing et al., 2018; Goldberg, 2005; Kraft, 2005).

Together, these art methodologies utilise alternative cognitive processing skills, to interpret and consolidate sparse information into a new coherent form (Medved et al., 2004). This suggests that the extra effort required to encode this information strengthens elaboration, leading to improved receptivity and retention of new information (Kim \& Olaciregui, 2008; Runco \& Sakamoto, 1999). In addition, art has been found to stimulate the enhanced memory of non-art related information, such as word pairs (Rosier et al., 2013). Therefore, these findings show that art making as opposed to art viewing enhances memory and effectively opens up a unique opportunity to improve educational outcomes in the more visual discipline of botany. Nevertheless, this preliminary research leaves many of the reasons for this greatly unknown concluding that far more research is required to strengthen the validity of these claims to allow for art's faithful incorporation into science education environments.

\section{Art in science}

The images created from studies of plant anatomy are heavily aesthetic and provide inspiration to many students. Developing that inspiration is an alternative way of engaging students in the discipline and should be encouraged at every opportunity. The fusion between these worlds creates a feedback loop on which the creative process inspired from scientific material develops a deeper enquiry-based understanding of the scientific material. Furthermore this fusion results in the wider community being exposed to science and provides a unique conduit between the laboratory and the general public; engaging a wider audience and simultaneously deconstructing the perceived disparate fields of Art and Science.

Historically, visual depictions in Biology have been shown to be essential in scientific research as a mode to visualise, document and form the basis for taxonomic descriptions of species and to support scientific theories. For example, the captivating works by the founder of modern neuroscience Santiago Ramón y Cajal, provided a gateway into the understanding of the functioning of neurons and the structure of the brain. So too, the incredibly detailed and intricate botanical illustrations of Ernest Haeckel, the influential botanist and explorer Sir Joseph Banks and many others, provided important education resources to support Darwinian theory and the enlightenment's quest for knowledge. These works also yielded immense qualities of awe. This explorative and emotive relationship to the natural world is an integral part of human behaviour and cultivating this should be encouraged to help combat the impacts of plant blindness on society. Nowadays, images taken by high-resolution fMRI scans can allow us to visualize brain activity with great accuracy, staining thousands of one kind of neuron with the targeted delivery of fluorescently-tagged proteins (Gorgolewski et al., 2015; Uemura et al., 2016). Likewise, the imaging of plant cells using a variety of different coloured dyes and more recently; fluorescent proteins and immunofluorescent antibody staining, has allowed scientists to explore the otherwise 
hidden molecular world of the cell and the functioning of whole plant systems. Importantly, these images and videos captured using these techniques are visually appealing and an engaging way to link students to the content at large. Along with this, these images stand alone as impressive works of art with many science journals (e.g. Science, Nature, and Cell) utilising this imagery for covers and articles. They also hold competitions in support of science-art practices.

The effectiveness of this form of science outreach highlights the great appeal for the aesthetics of biological imagery and the great advancement this brings to science education and engagement. As powerful as these images are however, as mentioned, the real influence of the visual in education is to engage students with the content through immersing them into the firsthand experience of drawing and art making.

\section{Botanical illustrations, drawing and art making as an educational tool}

At the height of the enlightenment and with the growth of scientific fervour, the exploration and recording of botanical life required taxonomic organisation of species often along with an associated illustration. Therefore, students and academics traditionally learned to draw their botanical observations in great detail. Now however, during laboratory and field work it is common practice for students to capture their observations by producing photos or micrographs. This is greatly beneficial as we have discussed that visual media is an important tool to reinforce student memory and learning. However, the shift in documentation from the careful and mindful observation of drawing to the capturing of microscopy images unfortunately produces a level of disconnection and students miss out on the active benefits on memory that drawing provides. Ultimately, this reduces the engagement and retention of information that relates to the intricacies of plant anatomy, such as the distribution of cell types and tissue types. This is where illustration and art making show their real benefits.

To clarify, the practice of botanical illustration is the accurate creation of imagery for the use of scientific documentation containing a high level of scientific detail. It is also celebrated as a legitimate form of art. However, it would be unrealistic to ask for students to meet these professional artistic standards. To achieve the educational benefits associated with producing an artwork, it is enough for students to create any illustrative drawing of specimens and/or images depicting the observed anatomies and morphologies. These may then be used further to create novel visual interpretations in the form of an artwork to enhance personal associations and further perpetuate content retention.

This process of visually digesting a plant specimen, or interpreting an image, to produce a work of art allows students to generate visual associations to the fine detail of forms found with subjective, personal and emotive perspectives. These may also be influenced by historical, cultural and ethnic lenses. Sharing of these interpretations allows for an exploration of the diversity of perception and visual interpretations of plant life and in turn, allows students to challenge and reflect on their own perceptions. The broadening of these perspectives bridges novel connections to the content, strengthening associations to facts (i.e. the 'semantic framework') (Khodor, Halme, \& Walker, 2004), along with one's personal relevance to the content. As opposed to language, art has its historical and biological link as a non-verbal communication system (Changeux, 2011) and encourages the development of healthy peer interactions and peer to peer learning (Jacobson et al., 2016). Therefore, through the process of making art students will develop novel science 
communication skills and as a by-product the works themselves also act as conduits for further scientific outreach.

From the educational benefit that drawing and art making provide, we stress the importance of honouring and re-kindling the historic traditions of illustration in botanical education. This may hold relevance to other streams of science education where science-art practices could be more readily available and incorporated into teaching curriculums. Alongside traditional teaching modes of delivery, the production of art would therefore function as a transdisciplinary teaching modality that strengthens students' memory and science communication skills. In a botanical context, this may lead to a deeper understanding of subdisciplines such as plant taxonomy, morphology and systematics. Further cultivating this ability to effectively communicate the significance, richness and variety of plant life may enhance educational outcomes and therefore help to reduce the prevalence of plant blindness within the broader community.

\section{An example of effective science-art collaboration within and beyond the classroom}

An exemplary science-art collaboration was created between the authors of this paper which led to the creation of an artwork exhibited at the University of Sydney, Verge Gallery in 2013. Botanical content and imagery was firstly explored within a laboratory setting and handmade microscope slides were created which included the sectioning of plant samples from a range of native flora. Staining was performed on the slides which allowed for a vast array of morphological features to be identified, drawn and photographed whilst being viewed under a microscope (Figure 1).

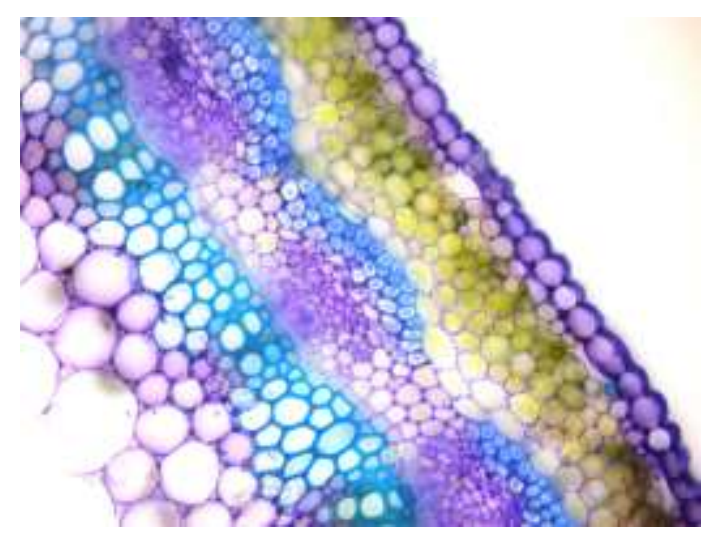

Figure 1: Transverse section of a stem of Medicago sp. stained with toluidine blue, creator Rosanne Quinnell, the University of Sydney (C).

Drawings made in the laboratory were used as the foundation of the development of a preliminary work titled Crosscut constructed from a handmade paper cutout placed upon a piece of floral fabric (Figure 2). This the artist believes "embodies and celebrates the greatly aesthetic qualities of cellular imagery within a traditional art-deco context" fusing borders between two seemingly disparate fields. 


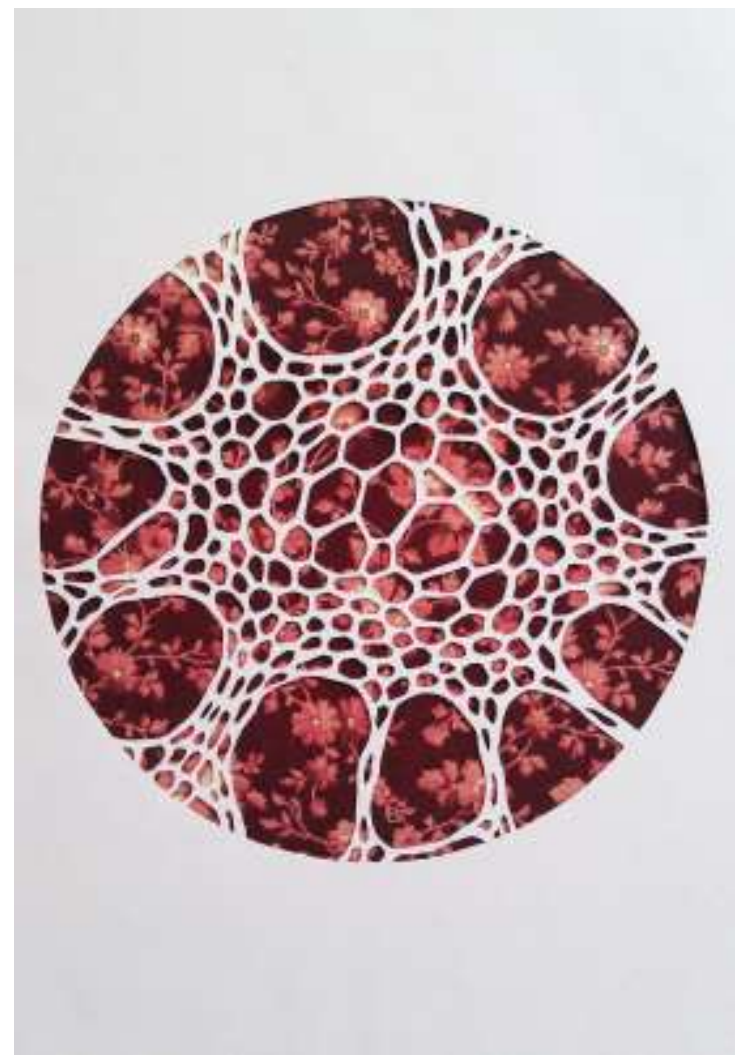

Figure 2: Crosscut by William Swann, 2012.

Cell Projection was then developed shortly after in 2013 (Figure 3). This work was created by taking the same botanical images of the plant cross-sections and transforming them into an audiovisual installation exhibited at The Verge Gallery, The University of Sydney in 2013. The process required the projection of these images onto a face and utilising the distortion of these patterns as outlines to be cutout from thin rice paper. A microscopy video from the laboratory session was then projected and illuminated through the cutout, leaving a silhouette of the images resting on a piece of hanging fabric. The fabric hung from the roof to the floor in the centre of the gallery space, moving gently as the audience roamed through the room creating an immersive an inquisitive interaction with the audience.

The overlay of images and depth, the perception of a flat space of cells, to a collection of faces and then finally to the wings of a butterfly, gives impetus to the notion of connectivity, that of life exchanged between all forms. From the scale of the micro to the macro, between botanical cells and to whole living organisms, between humans and all other life. The continuity of a spectrum of living entities from cell to being that we too easily disregard as irrelevant, is a profound and inherent insight that the scientific quest to understand the natural world around us unearths.

Through Cell Projection, the drawing and art making process was shown not only to solidify lasting connections with the learnt content, but also exposed the public audience to the imagery and insights of biology. Acting as a bridge it was shown to be a successful stimulus to broaden the 
publics' understanding of science, the sense of scientific enquiry and an exploration of our neglected relationship to plant life.

By fusing the aesthetic and scientific worlds together, a feedback loop is created from which the creative process inspired from scientific material develops a deeper enquiry-based understanding of the material itself. The neural and psychological underpinnings behind drawing, artmaking and memory are continually being uncovered and help to support science-art projects as effective additions to traditional modes of science education.
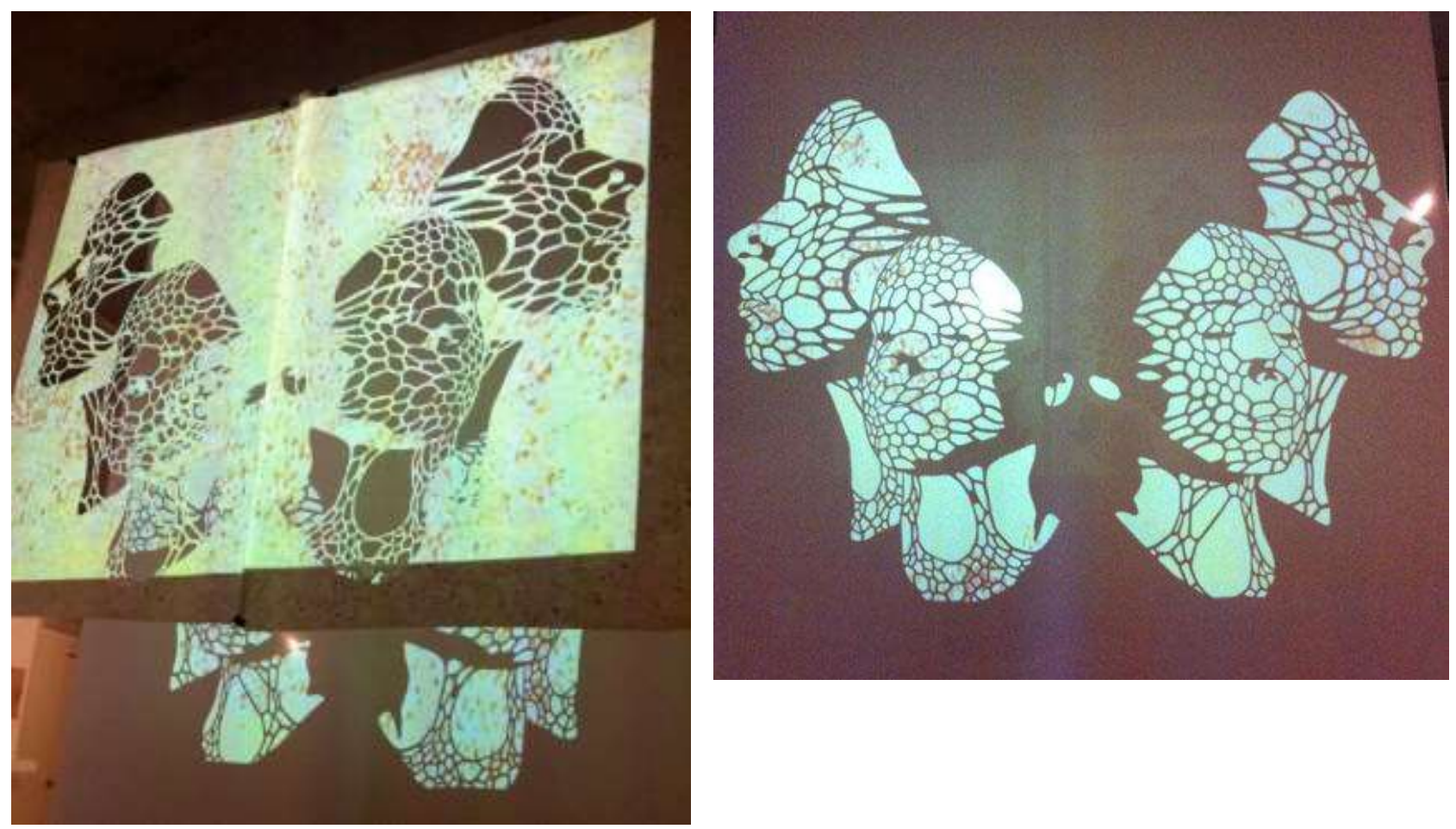

Figure 3: Cell Projection by William Swann, 2013.

\section{References}

Abbing, Annemarie, Ponstein, Anne, Hooren, Susan, de Sonneville, Leo, Swaab, Hanna, \& Baars, Erik. (2018). The effectiveness of art therapy for anxiety in adults: A systematic review of randomised and non-randomised controlled trials. In PLoS ONE (Vol. 13). https://doi.org/10.1371/journal.pone.0208716

Alberts, Bruce. (2009). Redefining Science Education. Science, 323(5913), 437 LP - 437. https://doi.org/10.1126/science.1170933

Allen, William. (2003). Plant Blindness. BioScience, 53(10), 926. https://doi.org/10.1641/00063568(2003)053[0926:PB]2.0.CO;2

Andrade, Jackie. (2010). What does doodling do? Applied Cognitive Psychology, 24(1), 100-106. https://doi.org/10.1002/acp.1561

Bigelow, James, \& Poremba, Amy. (2014). Achilles’ Ear? Inferior Human Short-Term and Recognition Memory in the Auditory Modality. In PloS ONE (Vol. 9). https://doi.org/10.1371/journal.pone.0089914

Bolwerk, Anne, Mack-Andrick, Jessica, Lang, Frieder R., Dörfler, Arnd, \& Maihöfner, Christian. (2014). How art 
International Journal of Innovation in Science and Mathematics Education, 27(7), 10-22, 2019

changes your brain: Differential effects of visual art production and cognitive art evaluation on functional brain connectivity. PLOS ONE, 9(7), e101035. Retrieved from https://doi.org/10.1371/journal.pone.0101035

Breidbach, Olaf. (2005). Art forms from the ocean: The radiolarian prints of Ernst Haeckel.

Briggs, John. (1982). Evaluating the quality of learning: The SOLO Taxonomy. New York: Academic Press.

Chan, Jason C. K., Manley, Krista D., Davis, Sara D., \& Szpunar, Karl K. (2018). Testing potentiates new learning across a retention interval and a lag: A strategy change perspective. Journal of Memory and Language, 102, 8396. https://doi.org/https://doi.org/10.1016/j.jml.2018.05.007

Changeux, Jean Pierre. (2011). The neuroscience of Art: A research program for the next decade? Mind, Brain, and Education, 5(1), 3-4. https://doi.org/10.1111/j.1751-228X.2011.01102.x

Clark, James M., \& Paivio, Allan. (2004). Extensions of the Paivio, Yuille, and Madigan (1968) norms. Behavior Research Methods, Instruments, \& Computers, 36(3), 371-383. https://doi.org/10.3758/BF03195584

Cohen, Michael A., Horowitz, Todd S., \& Wolfe, Jeremy M. (2009). Auditory recognition memory is inferior to visual recognition memory. Proceedings of the National Academy of Sciences of the United States of America, 106(14), 6008-6010. https://doi.org/10.1073/pnas.0811884106

Corballis, M. C. (1966). Rehearsal and decay in immediate recall of visually and aurally presented items. Canadian Journal of Psychology/Revue Canadienne de Psychologie, Vol. 20, pp. 43-51. https://doi.org/10.1037/h0082923

Council, National Research. (2009). A New Biology for the 21st Century. https://doi.org/10.17226/12764

Craik, Fergus I. M., \& Lockhart, Robert S. (1972). Levels of processing: A framework for memory research. Journal of Verbal Learning and Verbal Behavior, 11(6), 671-684. https://doi.org/https://doi.org/10.1016/S00225371(72)80001-X

Darby, Jaye T., \& Catterall, James S. (1994). The fourth R: The arts and learning. Teachers College Record, 96(2), 299-328.

Darley, W. Marshall. (1990). The essence of plantness. The American Biology Teacher, 52(6), 354 LP - 357. https://doi.org/10.2307/4449132

DeYoe, Edgar A., Lewis, James W., \& Beauchamp, Michael S. (2000). A comparison of visual and auditory motion processing in human cerebral cortex. Cerebral Cortex, 10(9), 873-888. https://doi.org/10.1093/cercor/10.9.873

E. Madden, Margaret, Baxter, Marsha, Beauchamp, Heather, Bouchard, Kimberley, Habermas, Derek, Huff, Mark, ... Plague, Gordon. (2013). Rethinking STEM education: An interdisciplinary STEAM curriculum. In Procedia Computer Science (Vol. 20). https://doi.org/10.1016/j.procs.2013.09.316

Eagleman, David, \& Brandt, Anthony. (2017). The Runaway Species. How Human Creativity Remakes The World. Catapult.

Einstein, A., Calaprice, A., \& Dyson, F. J. (2000). The expanded quotable Einstein. Retrieved from https://books.google.com.au/books?id=BVp3QgAACAAJ

Fairweather, James. (2010). Linking evidence and promising practices in science, technology, engineering, and mathematics (STEM) undergraduate education :A status report for The National Academies National Research Council Board of Science Education.

Fernandes, Myra A., Wammes, Jeffrey D., \& Meade, Melissa E. (2018). The surprisingly powerful influence of drawing on memory. Current Directions in Psychological Science, 27(5), 302-308. https://doi.org/10.1177/0963721418755385

Fritz, Jonathan, Mishkin, Mortimer, \& Saunders, Richard C. (2005). In search of an auditory engram. Proceedings of the National Academy of Sciences of the United States of America, 102(26), 9359 LP - 9364. https://doi.org/10.1073/pnas.0503998102

Geue, Kristina, Goetze, Heide, Buttstaedt, Marianne, Kleinert, Evelyn, Richter, Diana, \& Singer, Susanne. (2010). An overview of art therapy interventions for cancer patients and the results of research. Complementary Therapies in Medicine, 18(3), 160-170. https://doi.org/https://doi.org/10.1016/j.ctim.2010.04.001

Gloede, Michele. (2015). Visual memory is superior to auditory memory despite extensive auditory training.

Goldberg, Patricia D. (2005). Metacognition and art production as problem solving: A study of third grade students. Visual Arts Research, 31(2), 67-75. Retrieved from http://www.jstor.org/stable/20715385

Gorgolewski, Krzysztof J., Mendes, Natacha, Wilfling, Domenica, Wladimirow, Elisabeth, Gauthier, Claudine J., Bonnen, Tyler, ... Margulies, Daniel S. (2015). A high resolution 7-Tesla resting-state fMRI test-retest dataset with cognitive and physiological measures. Scientific Data, 2, 140054. Retrieved from https://doi.org/10.1038/sdata.2014.54

Gurnon, Daniel, Voss-Andreae, Julian, \& Stanley, Jacob. (2013). Integrating Art and Science in undergraduate education. In PLoS biology (Vol. 11). https://doi.org/10.1371/journal.pbio.1001491

Guy, Richard, \& Byrne, Bruce. (2013). Neuroscience and learning: Implications for teaching practice. Journal of Experimental Neuroscience, 7, 39-42. https://doi.org/10.4137/JEN.S10965 
Hills, Thomas T., Todd, Peter M., \& Jones, Michael N. (2015). Foraging in semantic fields: How we search through memory. Topics in Cognitive Science, 7(3), 513-534. https://doi.org/10.1111/tops.12151

Jacobson, Susan K., Seavey, Jennifer R., \& Mueller, Robert C. (2016). Integrated science and art education for creative climate change communication. Ecology and Society, 21(3). https://doi.org/10.5751/ES-08626-210330

Jensen, Arthur R. (1971). Individual differences in visual and auditory memory. Journal of Educational Psychology, 62(2), 123-131. https://doi.org/10.1037/h0030655

Kaas, Jon H. (2013). The evolution of brains from early mammals to humans. Wiley Interdisciplinary Reviews. Cognitive Science, 4(1), 33-45. https://doi.org/10.1002/wcs.1206

Kaimal, Girija, Ray, Kendra, \& Muniz, Juan. (2016). Reduction of cortisol levels and participants' responses following art making. Art Therapy: Journal of the American Art Therapy Association, 33(2), 74-80. https://doi.org/10.1080/07421656.2016.1166832

Kelley, Paul, \& Whatson, Terry. (2013). Making long-term memories in minutes: A spaced learning pattern from memory research in education. Frontiers in Human Neuroscience, 7, 589. https://doi.org/10.3389/fnhum.2013.00589

Khodor, Julia, Halme, Dina Gould, \& Walker, Graham C. (2004). A hierarchical Biology concept framework: A tool for course design. Cell Biology Education, 3(2), 111-121. https://doi.org/10.1187/cbe.03-10-0014

Kim, Paul, \& Olaciregui, Claudia. (2008). The effects of a concept map-based information display in an electronic portfolio system on information processing and retention in a fifth-grade science class covering the Earth's atmosphere. British Journal of Educational Technology, 39(4), 700-714. https://doi.org/10.1111/j.14678535.2007.00763.x

Kraft, Ulrich. (2005). Unleashing creativity. In Scientific American Mind (Vol. 16). https://doi.org/10.1038/scientificamericanmind0405-16

Leckey, J. (2011). The therapeutic effectiveness of creative activities on mental well-being: A systematic review of the literature. Journal of Psychiatric and Mental Health Nursing, 18(6), 501-509. https://doi.org/10.1111/j.13652850.2011.01693.x

Martindale, Colin. (1998). Biological bases of creativity. In Robert J. Sternberg (Ed.), Handbook of Creativity (pp. 137-152). https://doi.org/DOI: 10.1017/CBO9780511807916.009

Meade, Melissa E., \& Fernandes, Myra A. (2016). The drawing effect: Evidence for reliable and robust memory benefits in free recall AU - Wammes, Jeffrey D. The Quarterly Journal of Experimental Psychology, 69(9), 1752-1776. https://doi.org/10.1080/17470218.2015.1094494

Medved, Maria, Cupchik, Gerald, \& Oatley, Keith. (2004). Interpretive memories of artworks. In Memory (Hove, England) (Vol. 12). https://doi.org/10.1080/09658210244000441

Moga, Erik, Burger, Kristin, Hetland, Lois, \& Winner, Ellen. (2000). Does studying the Arts engender creative thinking? Evidence for near but not far transfer. In Journal of Aesthetic Education (Vol. 34). https://doi.org/10.2307/3333639

Mohedano-Moriano, A., Pro-Sistiaga, P., Arroyo-Jimenez, M. M., Artacho-Pérula, E., Insausti, A. M., Marcos, P., ... Insausti, R. (2007). Topographical and laminar distribution of cortical input to the monkey entorhinal cortex. Journal of Anatomy, 211(2), 250-260. https://doi.org/10.1111/j.1469-7580.2007.00764.x

Munoz-Lopez, Monica, MohedanoMoriano, Alicia, \& Insausti, Ricardo. (2010). Anatomical Pathways for Auditory Memory in Primates . Frontiers in Neuroanatomy , Vol. 4, p. 129. Retrieved from https://www.frontiersin.org/article/10.3389/fnana.2010.00129

Norretranders, T. (1998). The user illusion. New York: Viking.

Novak, Joseph D. (1990). Concept maps and Vee diagrams: Two metacognitive tools to facilitate meaningful learning. Instructional Science, 19(1), 29-52. https://doi.org/10.1007/BF00377984

Paivio, Allan, Rogers, T. B., \& Smythe, Padric C. (1968). Why are pictures easier to recall than words? Psychonomic Science, 11(4), 137-138. https://doi.org/10.3758/BF03331011

Ramsden, Paul. (1992). Learning to teach in higher education. https://doi.org/10.4324/9780203413937

Reed, Howard S. (1942). A short history of the plant sciences. New York: Ronald Press.

Root-Bernstein, Robert, Allen, Lindsay, Beach, Leighanna, Bhadula, Ragini, Fast, Justin, Hosey, Chelsea, ... Russ, Caitlin. (2008). Arts foster scientific success: Avocations of Nobel, National Academy, Royal Society, and Sigma Xi Members. In Journal of Psychology of Science and Technology (Vol. 1). https://doi.org/10.1891/19397054.1.2.51

Root-Bernstein, Robert, Bernstein, Maurine, \& Garnier, Helen. (1995). Correlations between avocations, scientific style, work habits, and professional impact of scientists. In Creativity Research Journal - CREATIVITY RES J (Vol. 8). https://doi.org/10.1207/s15326934crj0802_2

Rosier, James Tyler, Locker, Lawrence Jr, \& Naufel, Karen Z. (2013). Art and memory: An examination of the 
International Journal of Innovation in Science and Mathematics Education, 27(7), 10-22, 2019

learning benefits of visual-art exposure. North American Journal of Psychology, 15(2), 265-278.

Ross, Pauline, Taylor, Charlotte, Johnson, Elizabeth, \& Jones, Susan. (2013). Biology Standards Statement. https://doi.org/10.13140/RG.2.1.2266.8328

Rugg, Michael D. (1998). Memories are made of this. Science, 281(5380), 1151 LP - 1152. https://doi.org/10.1126/science.281.5380.1151

Runco, Mark A., \& Sakamoto, Shawn Okuda. (1999). Experimental studies of creativity. In Handbook of creativity. (pp. 62-92). New York, NY, US: Cambridge University Press.

Scaife, Michael, \& Rogers, Yvonne. (1996). External cognition: How do graphical representations work? In Int. J. Hum.-Comput. Stud. (Vol. 45). https://doi.org/10.1006/ijhc.1996.0048

Segarra, Verónica A., Natalizio, Barbara, Falkenberg, Cibele V, Pulford, Stephanie, \& Holmes, Raquell M. (2018). STEAM: Using the Arts to train well-rounded and creative scientists. Journal of Microbiology \& Biology Education, 19(1), 19.1.53. https://doi.org/10.1128/jmbe.v19i1.1360

Sparks, Sarah D. (2011). Science looks at how to inspire creativity. ERIC, 31(14), 1.

Stuckey, Heather L., \& Nobel, Jeremy. (2010). The connection between art, healing, and public health: a review of current literature. American Journal of Public Health, 100(2), 254-263. https://doi.org/10.2105/AJPH.2008.156497

Sweller, John. (1994). Cognitive load theory, learning difficulty, and instructional design. Learning and Instruction, 4(4), 295-312. https://doi.org/https://doi.org/10.1016/0959-4752(94)90003-5

Uemura, Takeshi, Mori, Takuma, Kurihara, Taiga, Kawase, Shiori, Koike, Rie, Satoga, Michiru, ... Tabuchi, Katsuhiko. (2016). Fluorescent protein tagging of endogenous protein in brain neurons using CRISPR/Cas9mediated knock-in and in utero electroporation techniques. Scientific Reports, 6, 35861. Retrieved from https://doi.org/10.1038/srep35861

Uno, Gordon E. (1994). The state of precollege botanical education. The American Biology Teacher, 56(5), 263 LP - 267. https://doi.org/10.2307/4449818

Van Meter, Peggy, \& Garner, Joanna. (2005). The promise and practice of learner-generated drawing: Literature review and synthesis. Educational Psychology Review, 17(4), 285-325. https://doi.org/10.1007/s10648-0058136-3

Wandersee, \& Schussler. (2000). Toward a theory of plant blindness. Plant Science Bulletin by Botanical Society of America.

Whiffen, Joshua W., \& Karpicke, Jeffrey D. (2017). The role of episodic context in retrieval practice effects. Journal of Experimental Psychology. Learning, Memory, and Cognition, 43(7), 1036-1046. https://doi.org/10.1037/xlm0000379

Winner, Ellen. (2007). Visual thinking in arts education: Homage to Rudolf Arnheim. In Psychology of Aesthetics, Creativity, and the Arts (Vol. 1). https://doi.org/10.1037/1931-3896.1.1.25 